\title{
Analysis and Implementation of a Switched Reluctance Generator in Connection with the Three-Phase Power Grid and Proposal of an Anti-Islanding Strategy
}

\author{
M. A. A. Freitas ${ }^{1}$, G. P. Viajante ${ }^{1}$, D. A. Andrade ${ }^{2}$, J. A. Santos Jr$^{1}$, V. R. Bernardeli ${ }^{1}$, L. G. W. Silva ${ }^{1}$, \\ E.N.Chaves ${ }^{1}$ and C.X.Rocha \\ ${ }^{1}$ Federal Institute of Education, Science and Technology of Goiás. \\ Energy Systems Research Center (Núcleo de Pesquisas em Sistemas de Energia - NuPSE) \\ Phone/Fax number: 5564 343152005, e-mail A: marcos.freitas@ifg.edu.br \\ ${ }^{2}$ Electric Drives Laboratory, Federal University of Uberlândia \\ Campus Santa Mônica, Uberlândia-MG, Brasil. \\ Phone/Fax number: 5534 3239-4411, e-mail: B. darizon@ ufu.br
}

\begin{abstract}
This paper presents a dynamics study of the Switched Reluctance Generator (SRG) dynamics when connected to a three-phase AC power grid. A mathematical model that includes magnetic saturation is used to represent the SRG, which is driven by an asymmetric half bridge converter. Output generated voltage is smoothed with a shunt capacitor leading to a DC link voltage. This voltage is regulated using a PI compensator that controls the magnetizing angle of the generator phases. It is shown that putting a freewheeling stage between the magnetizing and the demagnetizing states per phase, allows the best use for a better usage of the mechanical power in electromechanical conversion process. Injection of active power in the grid is performed by two PI compensators that determine the modulation indexes to each sinusoidal PWM modulators that drive the three phases of the converter. This work also proposes the implementation of an islanding detection method for distributed generation (DG) systems. This method is based on voltage and frequency parameters detection. It proved to be robust and useful to detect the islanding under different load conditions and the output of the power grid.
\end{abstract}

\section{Keywords}

Switched Reluctance Generator, Distributed Generation, Anti-islanding, Renewable energy, Grid Connection.

\section{Introduction}

The Switched Reluctance Generators (SRG) have been increasingly investigated as a potential electromechanical converter, due to its advantages of robust construction, easy cooling, ability to work with faulting phases and inherent adaptability to wide speed operation. Applications are reported in aerospace industry [1], hybrid vehicles and wind energy conversion systems [2]. In these cases, researches have focused in the SRG uses in low and medium speeds ranges. The control aim in these applications is to optimize the system to produce maximum output power [3], [4]. The distributed sources like winds and solar energy can bring significant benefits to the power grid operation due the generation plants can be placed at strategic points in the system, reducing the use of long transmission lines, therefore increasing the availability and reliability power. Power electronic converters are always required to interface these electrical sources of energy with AC power grid. In the same way, Switched Reluctance Machines (SRM), like motors or generators electronic power converters to operate. In the present investigation, was used a standard power converter to operate the generator called asymmetric half bridge converter (AHBC), and the power converter used to interface the DC voltage at the terminals of generator with the AC grid is a PWM converter.

The multilevel converters are well applied to interface high power wind energy conversion. In power grid they present good efficiency [5], lower switching losses and reduced electromagnetic interference as compared to conventional structures. However, to SRG application that runs with low or medium power wind generation systems, the multilevel converters are not adequate due the complex circuits control and implementation difficulties needed. It is necessary low cost and facilities to implement converter able to inject sinusoidal waveforms with low harmonic content on grid nowadays. This is the paper proposes using a PWM sinusoidal converter to interface the SRG with the AC grid [4]. 
The whole strategy to generate and injecting power in the grid occurs doing the control of the generated DC link voltage and the active power injection on grid. Regulated DC link voltage, obtained by controlling the magnetization angle of the generator phases, will be explained later. The active power injection on grid is performed controlling the output currents in a PWM converter. The synchronism with the AC power grid is obtained using a phase-locked loop algorithm (PLL). Modeling of the whole system is presented and discussed. Simulation results was included to illustrate.

In addition to expanding the electricity supply, the implantation of the small power generators bring numerous benefits, such as spraying power generation investments and the movement of local economies. It has been observed with the raise of distributed generation (DG) that the generated power does not always come from traditional sources.

Currently, the wind power sector is dominated by synchronous and asynchronous machines, but the switched reluctance generator has been the subject of several scientific and technological research, those indicate the SRG as an alternative to such application. Many works in literature are showing the SRG applied in wind power [1]-[5], however, few works presents the connection of these machines with the power grid [4]. Just a little bit literature reviews were observed this gap, mainly due to the fact that research on the reluctance machine operating as a generator is recent, and the needed to use in SRM special drives technologies to this purpose. Regarding the generation from alternative and its insertion in the electrical system supplies, the rules for distributed generation were published by many power agencies, regulating the use of these energy sources to meet the dealership networks from the surplus of consumers who own system own generation. In these cases, the injection of energy on grid, from the SRG, for example, have to meet the technical standards of synchronization on grid. This is necessary to avoid system disturbs, avoid losses and protect employees who might be operating the system.
The DG systems interact with the power grid distribution, and one of the main issues affecting their efficiency is the islanding phenomenon [6]-[12]. Thus, with this problem it becomes necessary a network fault detection system for disconnecting low power source to avoid damage to itself and workers of grid. This phenomenon occurs when the DG system continues to inject power to the network even when the power flow from the grid is interrupted. It may cause severe damages to the grid workers, equipment GD unit and own load islanded in the system. To detect and prevent such situations, some anti-islanding techniques were created [6]-[12]. These techniques have been studied considering the photovoltaic systems [8], [11], wind [7] and also to own hydropower from the synchronous generators [6], [9], [10]. It is observed, however, that this scenario has been changing and other power sources are emerging. One source, origin of several studies and publications in scientific circles, is the use of the reluctance machines applied to the power generation. This work presents a new study with detection of islanding coupled to the SRG's. The methodology to this implementation of anti-islanding system was based on a method that monitors the voltage and frequency values. This work contributes to the study and computational implementation of the method of islanding detection. All control system, is composed by a half-bridge converter, anti-islanding algorithms, generator and load. It was implemented computationally using the Matlab/Simulink software. Fig. 1 shown a schematic and details of control.

\section{SRG's Non Linear Model}

In order to simulate the whole system, the models of the subsystems are used. SRM's operate with cyclic and high variations in the phases flux linkages that lead to non linear ratio between phase flux linkage and current due to core saturation.

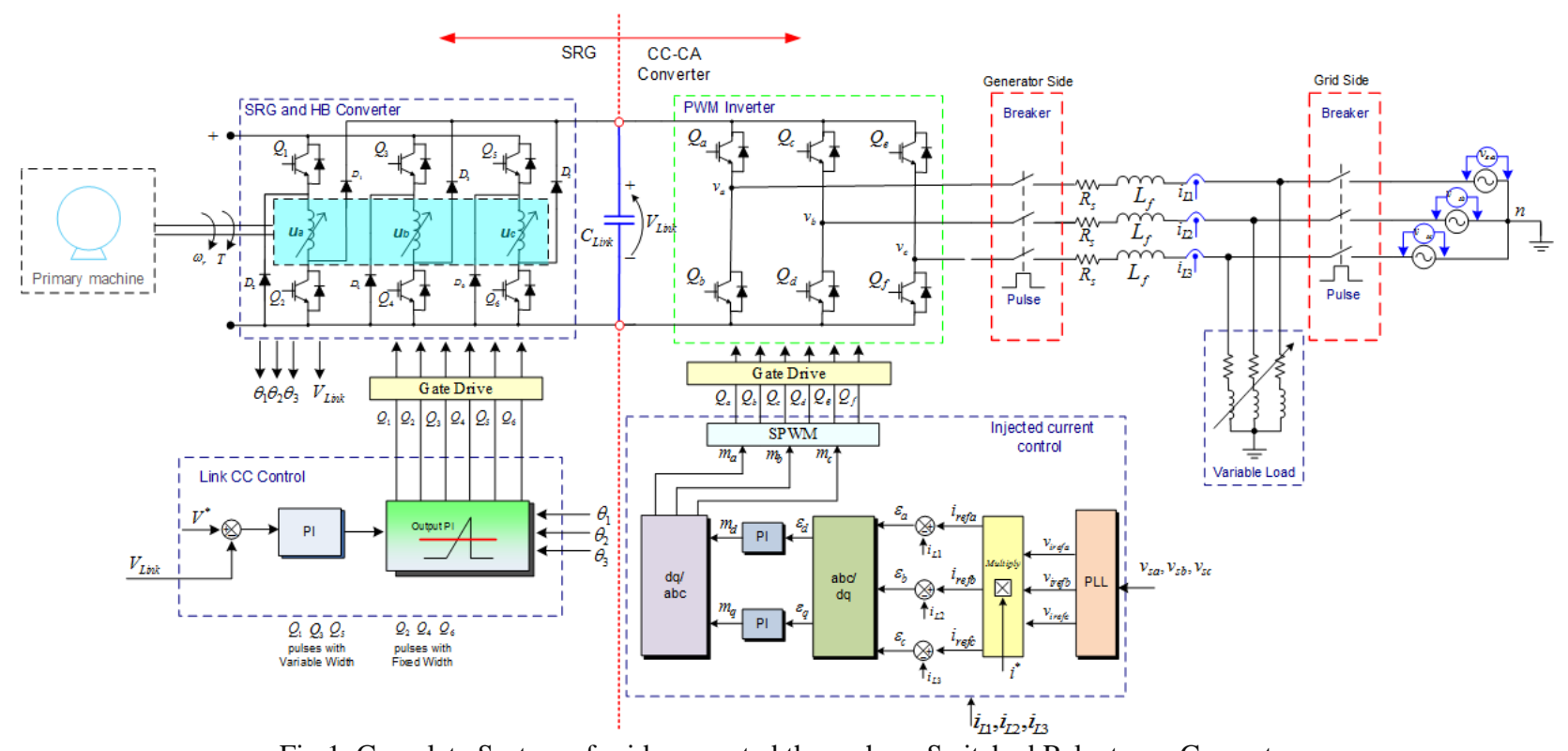

Fig.1. Complete System of grid-connected three phase Switched Reluctance Generator 
The mathematical model needs to consider this characteristic. As usual for reluctance machines, the magnetic coupling between phases was not considered. The equation of a phase SRG is described as:

$$
v=R i+\frac{d \lambda(i, \theta)}{d t}
$$

Writing an expanded form, the equation of the phase is given by

$$
v=R i+L(i, \theta) \frac{d i}{d t}+e
$$

Where $v$ is the applied voltage, $i$ is the phase current, $R$ is the phase resistance, $e=i \omega_{r} d L(i, \theta) / d \theta$ is the back emf, $\lambda(i, \theta)$ is the flux-linkage due to the current and position, $L(i, \theta)$ it the incremental phase inductance, $\theta$ is the rotor position.

Saturation effects are included in the model through the relation between the phase flux linkage and the corresponding phase current. Due to stator and rotor saliencies ratio is also depends of the rotor position. It is called incremental inductance and analytically expressed using a Fourier Series approximation [3].

The equation of the incremental inductance form to different values of currents and the rotor position is developed with an approximation using straight line segments shown in Fig. 2 and is given by:

$$
\begin{aligned}
& L(i, \theta)=\frac{1}{G} \sum_{j=1}^{m}\left(l_{(j+1)}\left(i, \alpha_{j}\right)+l_{j}\left(i, \alpha_{j}\right)\right)\left(\alpha_{(j+1)}-\alpha_{j}\right)+ \\
& \sum_{n=1}^{\infty}\left(\sum_{j=1}^{m}\left(l_{(j+1)}(i) A_{(j, n)}-l_{j}(i) B_{(j, n))}\right)\right) \cos \left(n P_{r} \theta\right)
\end{aligned}
$$

where:

$$
\begin{gathered}
A_{(j, n)}=\frac{2}{n \pi}\left(\sin \left(n P_{r} \alpha_{\left(j_{n}+1\right)}\right)+\frac{\cos \left(n P_{r} \alpha_{\left(j_{n}+1\right)}\right)-\cos \left(n P_{r} \alpha_{j}\right)}{n N_{r}\left(\alpha_{\left(j_{n}+1\right)}-\alpha_{j}\right)}\right) \\
B_{(j, n)}=\frac{2}{n \pi}\left(\sin \left(n P_{r} \alpha_{j}\right)+\frac{\cos \left(n P_{r} \alpha_{(j+1)}\right)-\cos \left(n P_{r} \alpha_{j}\right)}{n N_{r}\left(\alpha_{\left(j_{n}+1\right)}-\alpha_{j}\right)}\right),
\end{gathered}
$$

$m$ is the number of straight line segments, $n$ is the harmonic order, $P_{r}$ is the number of rotor poles, $G=2 \pi / P_{r}$ is the rotor pole pitch, $\theta$ is the rotor position, $l_{j}$ is the inductance to the $j^{\text {th }}$ segment, $\alpha_{j}$ is the position associated with this inductance [3], [4].

A polynomial own is used to represent the function $\mathrm{lj}(\mathrm{i}, \alpha \mathrm{j})$ for a given machine and is defined as:

$$
l_{j}\left(i, \alpha_{j}\right)=C_{3 j} i^{3}+C_{2 j} i^{2}+C_{1 j} i+C_{0 j}
$$

The mechanical torque produced by the machine is calculated as

$$
T_{e}=\frac{\partial W^{\prime}(i, \theta)}{\partial \theta}
$$

Where $W^{\prime}(i, \theta)$ is co-energy, given by:

$$
W^{\prime}(i, \theta)=\int_{0}^{i} \lambda(i, \theta) d i
$$

Considering the frictional losses viscous coefficient $D$, and moment of inertia $J$, the torque is obtained by:

$$
T_{m}=T_{\text {emag }}+J \frac{d \omega}{d t}+D \omega
$$

The mathematical model for the SRG is represented as a matrix of states through

$$
\dot{[}]=[L]^{-1}[V]-[L]^{-1}[R][I]
$$

The solution of the system allows complete SRG analysis [3], [4].

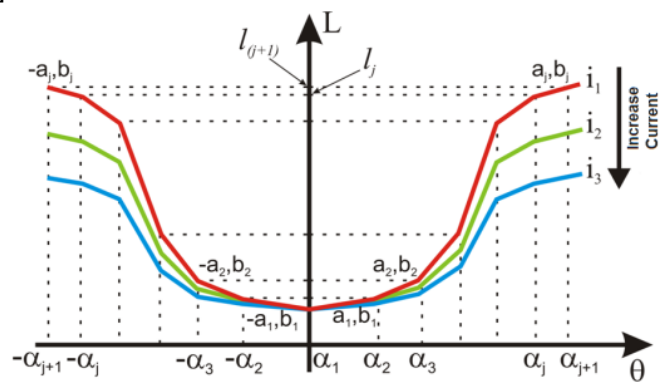

Fig.2. Line segments inductance versus rotor position

\section{Link Voltage Control}

To maintain constant the DC link voltage, the magnetization level of each SRG's phases is controlled. It is obtained by acting on the turn on and turn off angles. In this investigation the strategy is such $\theta_{o n}$ is kept constant (here fixed at $-3^{\circ}$ ) and the value of $\theta_{\text {off }}$ is governed through a PI compensator. The simulated machine and the prototype used are 6/4 which leads to an ideal conduction interval of $30^{\circ}$ for each phase. An asymmetric half bridge converter is used with an external AC voltage source in series with rectifier excites the generator. The PI controller controls the turn off angle of the converter top switch, while the bottom switch conducts through $30^{\circ}$. In the interval between the turning off of the top and bottom switches, occurs a period where the converter does not deliver power to the load, while the electromechanical conversion continues. This increases the power stored in the phase and was observed to be a way of improving the electromechanical conversion process as compared to the situation where the two switches are turned off at the same time [4]. We call it a "flux boosting" period, and it is different from a standard freewheeling stage, because in that there is the input of energy from the mechanical source. Following this period of free generation, with the opening of the bottom switch, the energy stored in the phase is transmitted to the load. This comprises the demagnetization period. So a phase cycle includes three stages: excitation, flux boosting and demagnetization. Switches states can be seen in Fig.3. The control strategy of the DC link is shown in Fig.4.

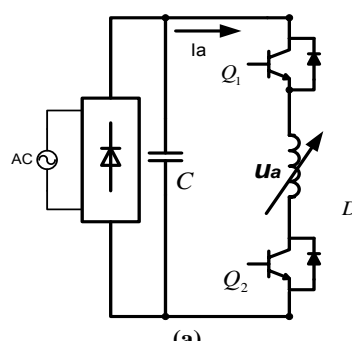

(a)

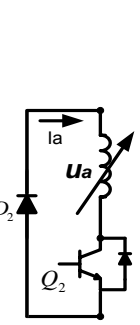

(b)

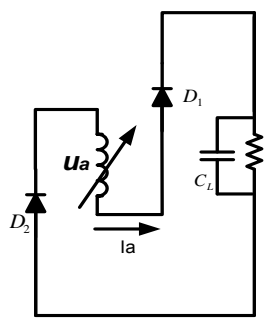

(c)
Fig.3. Region of excitation (a) Flux boosting Region (b) Phase demagnetization Region (c). 


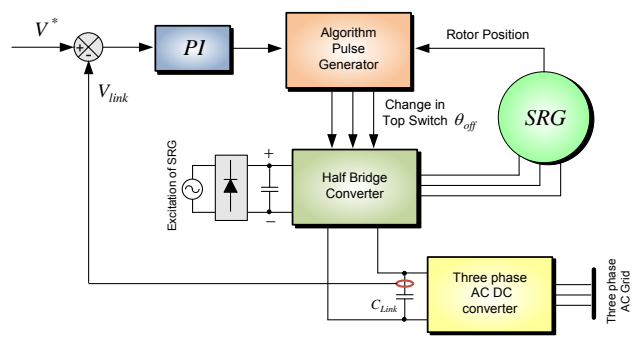

Fig.4. DC link voltage control

\section{DC-AC Converter}

\section{A. Controller output current of DC-AC Converter}

The interfacing between the SRG and the AC grid three phases is done through a current controlled PWM inverter as shown in Fig. 1. In the DC link, the voltage of the capacitor is kept $V_{\text {link }}$ regulated by control strategy like presented in Section III.

The output currents $i_{L 1}, i_{L 2}$ and $i_{L 3}$ are synthesized by the currents controller, which compensates the error signal between the currents $i_{L 1}, i_{L 2}$ and $i_{L 3}$ in the coupling inductors $L_{f}$ and the reference current $i_{\text {refa }}, i_{\text {refb }}$ and $i_{\text {refc }}$. The reference currents are generated by multiplying $i *$ (which represents the peak current to be injected) to the synchronized sinusoidal unitary signal coming from the PLL according to Fig. 5.

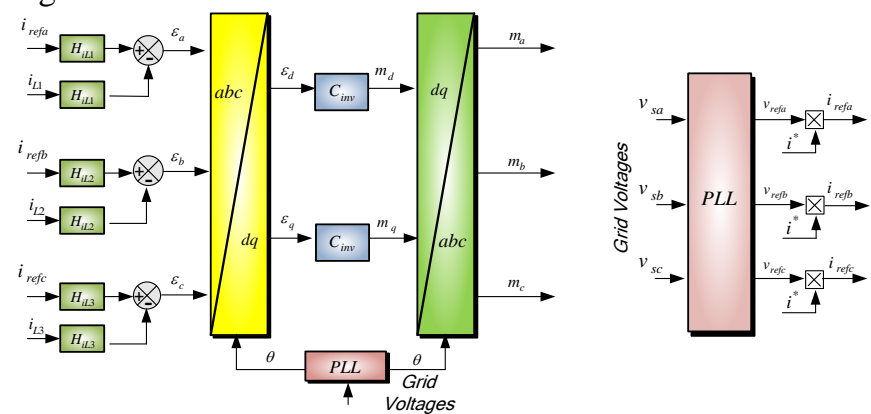

Fig.5. Controlling the output current (DC-AC converter) and PLL.

The peak values of the reference currents determine how much active power is inject on grid. As the $i_{L 1}, i_{L 2}$ and $i_{L 3}$ currents goes in phase with the grid voltage, only active power is delivered. The current controller of Fig. 5 employs two PI compensators $\left(C_{i n v}\right)$ for the $d$ and $q$ currents. The $d q$ $a b c$ and $a b c-d q$ transformations are presented in equations $9,10,11$ and 12. The transformations use the angle $\theta$ (syncronized with the grid voltages) provided by the phaselocked loop (PLL).

$$
\begin{aligned}
& {\left[\begin{array}{c}
i_{\alpha} \\
i_{\beta}
\end{array}\right]=\sqrt{\frac{2}{3}} \cdot\left[\begin{array}{ccc}
1 & -1 / 2 & -1 / 2 \\
0 & \sqrt{3} / 2 & -\sqrt{3} / 2
\end{array}\right] \cdot\left[\begin{array}{l}
i_{a} \\
i_{b} \\
i_{c}
\end{array}\right] \quad(09) \quad\left[\begin{array}{l}
i_{d} \\
i_{q}
\end{array}\right]=\left[\begin{array}{cc}
\cos \theta & \sin \theta \\
-\sin \theta & \cos \theta
\end{array}\right] \cdot\left[\begin{array}{c}
i_{\alpha} \\
i_{\beta}
\end{array}\right]} \\
& {\left[\begin{array}{c}
i_{\alpha} \\
i_{\beta}
\end{array}\right]=\left[\begin{array}{cc}
\cos \theta & -\sin \theta \\
\sin \theta & \cos \theta
\end{array}\right] \cdot\left[\begin{array}{l}
i_{d} \\
i_{q}
\end{array}\right] \quad \text { (11) }\left[\begin{array}{l}
i_{a} \\
i_{b} \\
i_{c}
\end{array}\right]=\sqrt{\frac{2}{3}} \cdot\left[\begin{array}{cc}
1 & 0 \\
-1 / 2 & \sqrt{3} / 2 \\
-1 / 2 & -\sqrt{3} / 2
\end{array}\right] \cdot\left[\begin{array}{c}
i_{\alpha} \\
i_{\beta}
\end{array}\right]}
\end{aligned}
$$

\section{B. DC-AC Converter Modeling}

The process of modeling the three-phase grid-connected converter with controlled output currents is based on the equivalent circuit shown in Fig. 6.

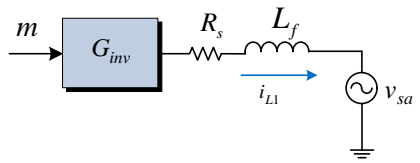

Fig.6 Equivalent circuit of the grid-connected converter output.

Considering that the converter is driven by a sinusoidal PWM modulator with symmetrical triangular carrier, it can be modeled as a constant gain, being $m$ the PWM modulation index. Each phase of the converter is analyzed independently with the equivalent circuit of Fig. 6 and the inductor current transfer function is:

$$
G_{i n v}(s)=\frac{2 v_{\text {Link }}}{s L_{f}+R_{s}}
$$

From the transfer function of the DC-AC converter, equation 13, and the values of Converter Parameters Connected to Power Grid was possible to design a compensator that guarantees good stability to the converter. The converter parameter are: $H_{i L}=1 / 30, L_{f}=7 \mathrm{mH}, R_{s}=0,3$ $\Omega, v_{\text {Link }}=450 \mathrm{~V}$ and $F_{c h}=10 \mathrm{KHz}$.

$$
C_{i n v}(s)=0,59096 \cdot \frac{(s+5,646 e 3)}{s}
$$

The Bode plot of the compensated system is shown in Fig.7. The crossover frequency is chosen to be $1.0 \mathrm{kHz}$ which represents $1 / 10$ of the switching frequency. In this case, the phase margin of the system is $50.1^{\circ}$. The synchronization with the grid is done with a digital PLL phase shown in Fig 8.

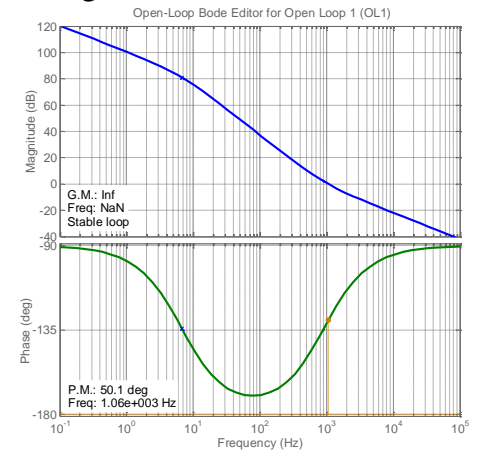

Fig.7. Bode diagram of the compensated system

\section{PLL schematic (Phase Locked Loop)}

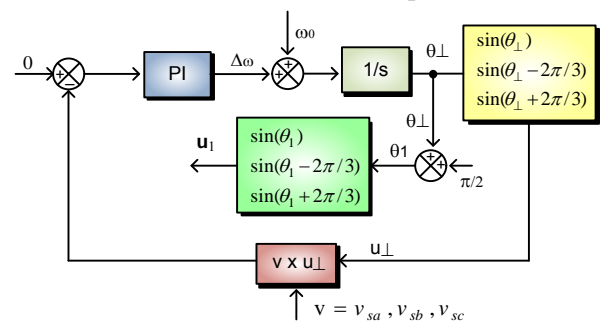

Fig.8. PLL Schematic

It is based on the scalar product between the vector $\mathbf{v}$ and orthogonal voltage vector $\mathbf{u} \perp$. When the PLL is synchronized with the mains voltage the two vectors are orthogonal and their product is zero. The PI compensator acts to minimize the error $\varepsilon=0-\mathbf{v} \times \mathbf{u} \perp$, i.e. to cancel the scalar product, and generates the component $\Delta \omega$. The integration of the angular frequency $\omega=\Delta \omega+\omega_{0}$ results in the angle $\theta \perp$. The vector $u_{l}$ corresponds to the sinusoid unit synchronized with the mains voltage and is used to generate the reference current of the PWM inverter. 


\section{Results}

The whole system shown in Fig.1 was simulated together, i.e. the SRG provides a regulated voltage at the DC link and the current PWM inverter injects the synthesized current in the grid through the current controller action. In this case, the controlled SRG generated voltage and the output current of the inverter work uncoupled. The results are for a 6X4 SRG whose parameters are shown in Table 1. It was also implemented anti-islanding detection technique based on the monitoring of the voltage and frequency signals. If an islanding is detected, breakers the generator side and interrupt system on grid. The simulation tests were conducted with the following criteria: reference voltage controller $450 \mathrm{~V}$ and rotor speed fixed at $1500 \mathrm{rpm}$ in SRG. The peak reference currents starts with $10 \mathrm{~A}$ and after 2 seconds steps to $20 \mathrm{~A}$ and after 2 seconds returns to 10A. The whole system was simulated for 6 seconds. Fig. 9 shows the behavior of the DC link voltage during the transient charging. It is observed that the reference value $(450 \mathrm{~V})$ was properly maintained. This test demonstrated that the voltage controller is able to maintain the generated power near the reference value even during transient load. To the same situation, Fig.9 shows the current in one phase of the generator. It was taken zoom of the SRG phase current and the corresponding trigger signals to the asymmetric bridge converter switches, and shown in Fig.10. Regarding power, measurements were made at the entrance of the DC-AC converter, i.e., the DC link and at the inverter output where connection to the grid happens.
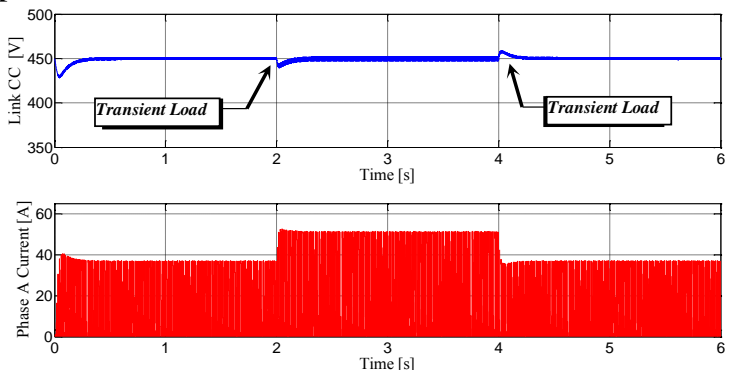

Fig.9. SRG generated voltage (top) and phase current (below)

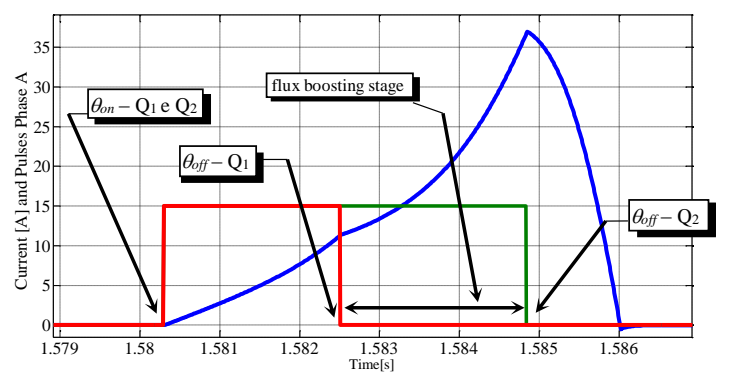

Fig.10. Phase current and Q1 and Q2 pulses.

Fig.11 shows the behavior of active power injected into the grid and the input power of the converter. For a peak reference output current of the DC-AC converter $10 \mathrm{~A}$ in the power delivered to the grid is approximately $2400 \mathrm{~W}$ per two seconds. When the reference changes to $20 \mathrm{~A}$ power is 4800 W. Fig. 12 shows three-phase currents injection behavior with power step. The shape of the current injected into the AC grid (one phase) and mains voltage waveform are shows in Fig.14. It can be seen that the current is in phase with the voltage, therefore only active power is delivered on grid. It was identified that the THD (Total Harmonic Distortion) of the current injected on grid was $0.34 \%$.

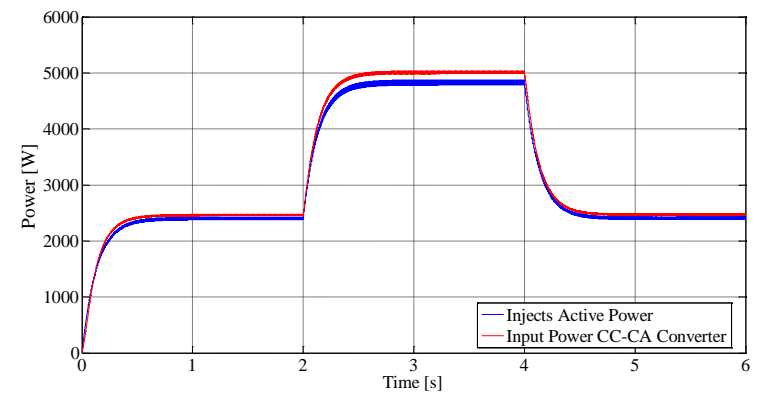

Fig.11. DC-AC converter input and output power

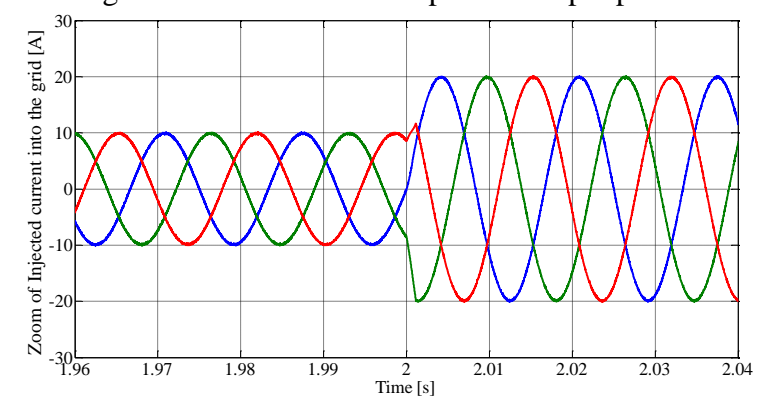

Fig.12. Zoom of Three-phase currents injected into the grid

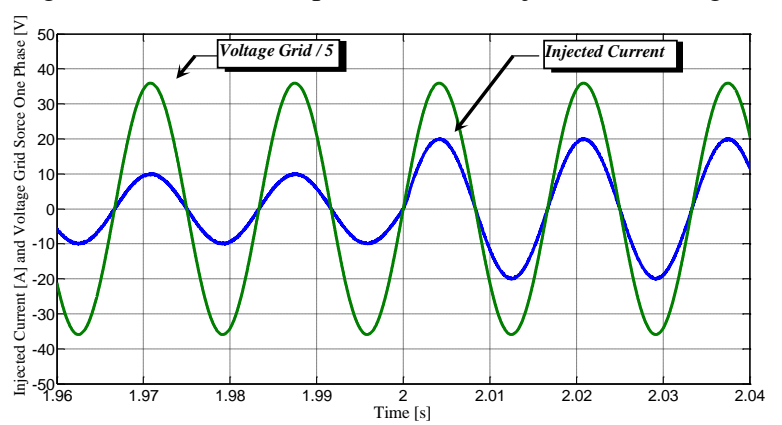

Fig.13. Injected current and Voltage Grid one phase

Fig. 14 shown the voltage in one phase (black trace), the current in step (red trace) and the control signal when disables the generation after the detection of the islanding. The islanding happens in the output of the power grid causing a substantial increase in tension and variation in the PLL output frequency. The identification method immediately detects these variations and sends a signal to disable the power supply output from the SRG. After the opening of the DG circuit breaker (at time $t=1 \mathrm{~s}$ ) both the current and voltage drops instantly to zero. Fig. 15 shows the active and reactive power of the load. It is initially inserted one $500 \mathrm{~W}$ load (until $\mathrm{t}=0.3 \mathrm{~s}$ ). Subsequently, at $\mathrm{t}$ $=0,3 \mathrm{~s}$, a load step is applied, causing the same to operate at $1000 \mathrm{~W}$. At time $\mathrm{t}=0,6 \mathrm{~s}$ the load becomes equal to $1500 \mathrm{~W}$ and $\mathrm{t}=0,9 \mathrm{~s}$ load returns to its initial value of $500 \mathrm{~W}$. At time $t=1 \mathrm{~s}$ the utility power grid is removed and the breaker of DG is disabled, negating the current, voltage, and consequently taking the active and reactive power to zero. The frequency measurement is made from a PLL and the results are shown in Fig. 16. It is noted that the load variations (at $\mathrm{t}=0.3 \mathrm{~s}, \mathrm{t}=0,6 \mathrm{~s}$ and $\mathrm{t}=0,9 \mathrm{~s}$ ) practically does not change the frequency. Since the removal of the power grid, at $\mathrm{t}=1 \mathrm{~s}$, causes a significant change in frequency, right now the breaker of DG is disconnected by protecting the system and avoiding accidents. 


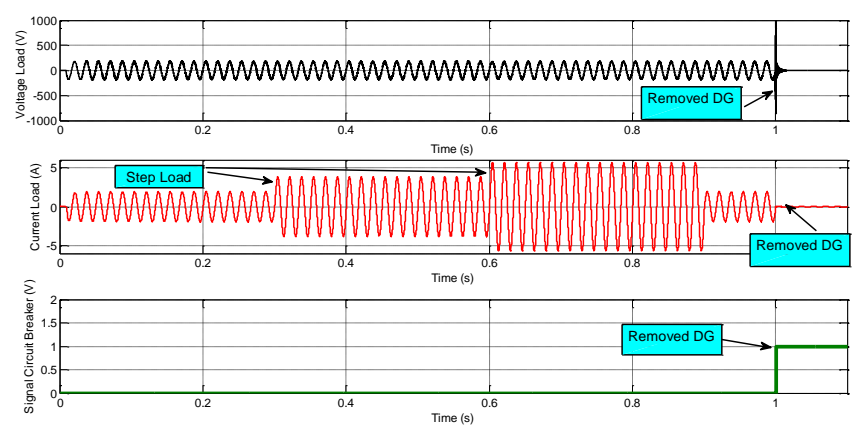

Fig. 14. Voltage (black), Current (red) and Signal brake (green)
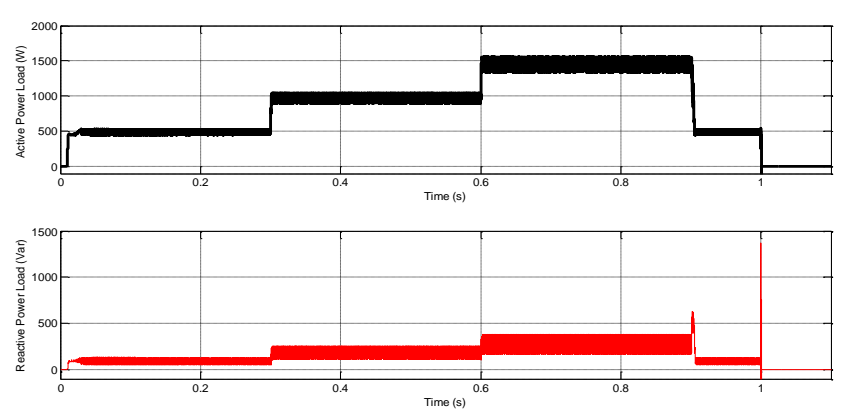

Fig. 15. Active (black) and Reactive (red) Power Load

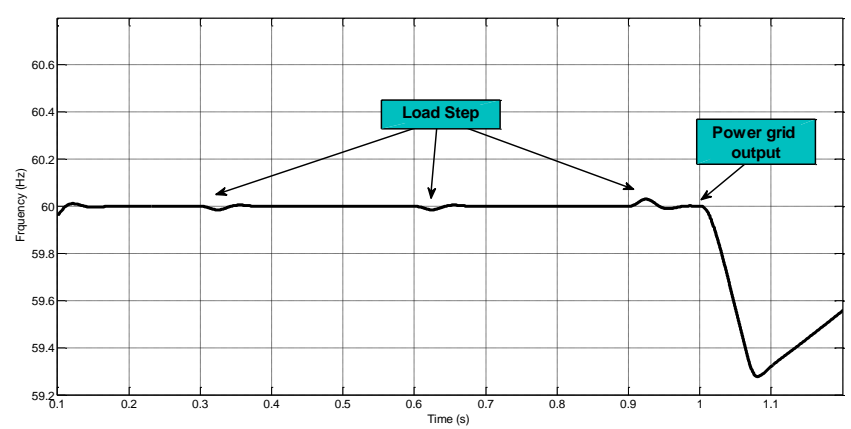

Fig. 16. Frequency measurement - PLL output

\section{Conclusion}

The investigations reported in this paper shown that the anti-islanding can be applied satisfactorily in DG systems using the SRG as a power source. The islanding is detected by monitoring system parameters and is identified under various types of load. The effective value measures the voltage between phases and frequency were made. The voltage was measured from sensor and the frequency was monitored from a PLL. The islanding is detected in a very fast time, enabling quick shutdown to distributed generation. An investigation of the availability of power generation using a SRG generator and the corresponding connectivity to the AC mains was presented. The strategy of control devises independent control of the generated voltage and the current delivered to the AC grid. Conventional control techniques are used and low complexity control schemes are used. Interface of electromechanical conversion and tree-phase AC grid is realized with active power injection. Simulation results to complete system were presented and modeling of the subsystems presented. The experimental execution was being implanted and presented its issues, indicating the viability of the proposed system. The experiments for the Switched Reluctance Generator connected to single-phase should have been made in future works. Now, it remains to implement the tree-phase system.
APPENDIX

TABLE 1

Data Prototype SRG 6x4

\begin{tabular}{ll}
\hline \hline Characteristics & Values \\
\hline Output Power & $7.5 \mathrm{HP}$ \\
Viscous Friction & $0.006 \mathrm{~N} . \mathrm{m} . \mathrm{s}$ \\
Inductance (Aligned Position) & $0.77961 \mathrm{H}$ \\
Inductance (Not Aligned position) & $0.00262 \mathrm{H}$ \\
Moment of Inertia & $0.04806 \mathrm{~g} . \mathrm{m}^{2}$ \\
Phase winding resistance & $0.5 \Omega$ \\
\hline \hline
\end{tabular}

\section{References}

[1] Y.Chang, C.M. Liaw, "On the design of power circuit and control scheme for switched reluctance generator", Transactions on Power Electronics, vol. 23, no. 1, 2008.

[2] Y.C. Chang, C.M. Liaw. "Establishment of a SwitchedReluctance Generator-Based Common DC Microgrid System", IEEE Transactions on Power Electronics, Vol. 26, No. 9, pp. 2512-2527, September 2011.

[3] D. A. Andrade, R. Krishnan, "Characterization of Switched Reluctance Machines Using Fourier Series Approach", in Proc. 36th IEEE Ind. Appl. Annu. Meeting, pp. 48-54, Sep. 2001.

[4] G.P.Viajante, et all, "Estratégia para Melhoria da Eficiência da Conversão Eletromecânica de Energia do GRV", IEEE Eletrônica de Potência, v. 16, N4, p. 367-375, 2011.

[5] Cardenas, R., at. al., "Control of a switched reluctance generators for variable-speed wind energy applications" IEEE Trans. on energy conversion, Vol. 20, N ${ }^{\circ}$ 4, Dec. 2005.

[6] Motter, D.; Vieira, .C.M.; Coury, D.V."Development of frequency-based anti-islanding protection models for synchronous distributed generators suitable for real-time simulations", Generation, Transmission \& Distribution, IET,2015, Volume: 9, Issue: 8 p.708 - 718, DOI: 10.1049/ietgtd.2014.0390

[7] Abbey, C.; Brissette, Y.; Venne, P., "An Autoground System for Anti-Islanding Protection of Distributed Generation", IEEE Transactions on Power Systems, 2014, Volume: 29, Issue: 2 , p. 873 880, DOI: 10.1109/TPWRS.2013.2284670.

[8] Yafaoui, A.; Bin Wu; Kouro, S., "Improved Active Frequency Drift Anti-islanding Detection Method for Grid Connected Photovoltaic Systems", IEEE Transactions on Power Electronics, 2012, Volume: 27, Issue: 5, p. 2367 2375, DOI: 10.1109/TPEL.2011.2171997.

[9] Salles, D.; Freitas, W.; Vieira, J.C.M.; Wilsun Xu, "Nondetection Index of Anti-Islanding Passive Protection of Synchronous Distributed Generators", IEEE Transactions on Power Delivery, 2012, Volume: 27, Issue: 3, p. 1509 1518, DOI: 10.1109/TPWRD.2012.2190624

[10] Bakhshi, M.; Noroozian, R.; Gharehpetian, G.B., "AntiIslanding Scheme for Synchronous DG Units Based on TuftsKumaresan Signal Estimation Method", IEEE Transactions on Power Delivery, 2013, Volume: 28, Issue: 4, p. 2185 2193, DOI: 10.1109/TPWRD.2013.2271837

[11] Seo, G.-S.; Lee, K.-C.; Cho, B.-H., "A New DC AntiIslanding Technique of Electrolytic Capacitor-Less Photovoltaic Interface in DC Distribution Systems", IEEE Transactions on Power Electronics, 2013, Volume: 28, Issue: 4, p. 1632-1641, DOI: 10.1109/TPEL.2012.2208226

[12] Velasco de la Fuente, D.; Trujillo Rodriguez, C.L.; Narvaez, E.A., "Review of Anti-Islanding Methods: Analysis by Figures of Merit Tools for Controllers Reconfiguration in Microgrids", Latin America Transactions, IEEE (Revista IEEE America Latina), 2015, Volume: 13, Issue: 3, p. 679 686, DOI: 10.1109/TLA.2015.7069092. 